06;15

\title{
Исследование влияния содержания водорода на проводимость нанокристаллических алмазных пленок
}

\author{
() О.А. Иванов ${ }^{1}$, А.Л. Вихарев ${ }^{1, \uparrow, ~ С . А . ~ Б о г д а н о в ~}{ }^{1}$, Н.М. Овечкин ${ }^{1}$, В.П. Логинов ${ }^{2}$, Ю.А. Яковлев ${ }^{2}$, \\ А.Я. Вуль ${ }^{3}$ \\ 1 Федеральный исследовательский центр Институт прикладной физики РАН, Нижний Новгород, Россия \\ ${ }^{2}$ Институт проблем машиноведения РАН, Санкт-Петербург, Россия \\ ${ }^{3}$ Физико-технический институт им. А.Ф. Иоффре РАН, Санкт-Петербург, Россия \\ I E-mail: val@appl.sci-nnov.ru
}

Поступило в Редакцию 16 июня 2021 г.

В окончательной редакции 11 октября 2021 г.

Принято к публикации 11 октября 2021 г.

\begin{abstract}
Приводятся результаты исследования электропроводности нанокристаллических алмазных пленок толщиной 0.5-0.6 $\mu \mathrm{m}$, выращенных на кремнии $\mathrm{Si}(100)$ методом плазмохимического осаждения из газовой фазы в смесях водорода и метана, водорода, метана и кислорода при их различном содержании. Методом нагрева в вакууме с использованием анализатора водорода AB-1 определена концентрация водорода в выращенных в различных условиях пленках и установлена связь между содержанием водорода в пленках и их проводимостью. Показано, что высокотемпературная обработка, например, в вакууме при температуре $600^{\circ} \mathrm{C}$ приводит к десорбции водорода из пленок и существенному возрастанию их сопротивления.
\end{abstract}

Ключевые слова: нанокристаллический алмаз, тонкие алмазные пленки, электрические свойства пленок, содержание водорода.

DOI: 10.21883/PJTF.2022.02.51920.18923

Интерес к изучению свойств нанокристаллических алмазных (НКА) пленок, выращиваемых методом плазмохимического осаждения из газовой фазы, в значительной мере обусловлен широтой их возможного применения [1]. Такие пленки обладают высокой теплопроводностью, химической и радиационной стойкостью, высокими эмиссионными характеристиками, могут быть легированы и поэтому представляют интерес для создания приборов микроэлектроники, микроэлектромеханических структур (МЭМС) и защитных покрытий [2-5]. Легированные НКА-пленки, имеющие значительную проводимость и осаждаемые в газовых смесях при добавлении азота или бора, или фосфора, активно изучаются и имеют обширную библиографию [2-5]. В то же время нелегированные НКА-пленки с высоким удельным сопротивлением менее изучены. Эти пленки вызывают интерес для применения в качестве диэлектрических слоев в высокочастотных МЭМС-переключателях [6]. Такие пленки с контролируемым током утечки могут, например, устранить проблему зарядки, наблюдаемую в устройствах с оксидными диэлектрическими слоями, используемыми в высокочастотных емкостных переключателях. Нелегированные НКА-пленки могут обладать хорошими изоляционными свойствами, высокой теплопроводностью и удельным сопротивлением, близким к удельному сопротивлению пленок диоксида кремния порядка $10^{14} \Omega \cdot \mathrm{cm}[7]$.

В нашей работе [8] было показано, что существенное влияние на электрические характеристики нелегированных НКА-пленок оказывают условия синтеза и состав газовой смеси, в значительной мере определяющие размер кристаллитов и долю неалмазной $\left(s p^{2}\right)$ фазы в пленке. По своей природе НКА-пленки представляют собой дефектный алмаз, проводимость которого зависит как от количества дефектов и ионизируемых сайтов непосредственно в кристаллитах, так и от наличия неалмазного углерода на границах кристаллитов. Известно, что, подбирая условия CVD-синтеза, можно существенно уменьшить долю неалмазного углерода в пленке и соответственно ее электропроводность [8]. В то же время при использовании водород-метановой газовой смеси водород, проникающий внутрь НКА-пленки в процессе ее роста, также может способствовать сохранению электрической проводимости осаждаемой пленки. Целью настоящей работы является определение содержания водорода в тонких нелегированных НКА-пленках с высоким удельным сопротивлением, выращенных при тех же условиях, что и в [8], а также изучение влияния водорода на проводимость таких пленок. Из литературы известны примеры определения концентрации водорода в пленках методом спектроскопии ядер отдачи (elastic recoil detection) [9], который является довольно трудоемким. В настоящей работе был применен простой метод определения концентрации водорода в пленках с использованием промышленного анализатора водорода AB-1.

Для исследований были подготовлены образцы НКА-пленок, осажденных на кремниевые подложки $\mathrm{Si}(100)$ размером $20 \times 20 \times 0.5 \mathrm{~mm}$ с предварительно нанесенным на них в ультразвуковой ванне слоем частиц детонационного наноалмаза $(5 \mathrm{~nm})$, играющего роль центров зародышеобразования. Плотность центров роста алмаза достигала $10^{12} \mathrm{~cm}^{-2}$, что способствовало об- 
Таблица 1. Режимы осаждения НКА-пленок

\begin{tabular}{|c|c|c|c|c|c|}
\hline Образцы & $\begin{array}{c}\text { Состав газовой } \\
\text { смеси } \\
\mathrm{H}_{2} / \mathrm{CH}_{4} / \mathrm{O}_{2}, \mathrm{sccm}\end{array}$ & $\begin{array}{c}\text { Температура } \\
\text { подложки, } \\
{ }^{\circ} \mathrm{C}\end{array}$ & $\begin{array}{l}\text { Мощность, } \\
\text { kW }\end{array}$ & $\begin{array}{c}\text { Давление, } \\
\text { Torr }\end{array}$ & $\begin{array}{c}\text { Толщина } \\
\text { пленки, } \\
\text { nm }\end{array}$ \\
\hline 1 и $1 A$ & $\begin{array}{c}200 / 16 / 0 \\
\left(\mathrm{CH}_{4} / \mathrm{H}_{2}=8 \%\right)\end{array}$ & 710 & 2.2 & 35 & 560 \\
\hline 2 и $2 A$ & $\begin{array}{c}400 / 2 / 0 \\
\left(\mathrm{CH}_{4} / \mathrm{H}_{2}=0.5 \%\right)\end{array}$ & 720 & 4.0 & 37 & 580 \\
\hline 3 и $3 A$ & $\begin{array}{c}400 / 2 / 0.4 \\
\left(\mathrm{CH}_{4} / \mathrm{H}_{2}=0.5 \%\right. \\
\left.\mathrm{O}_{2} / \mathrm{H}_{2}=0.1 \%\right)\end{array}$ & 720 & 2.25 & 35 & 560 \\
\hline
\end{tabular}

Таблица 2. Результаты измерения содержания водорода в НКА-пленке

\begin{tabular}{c|c|c|c|c|c|c}
\hline Образец & $\begin{array}{c}\text { Отжиг в } \\
\text { вакууме }\end{array}$ & $T_{1},{ }^{\circ} \mathrm{C}$ & $Q_{1}, \mathrm{ppm}$ & $T_{2},{ }^{\circ} \mathrm{C}$ & $Q_{2}, \mathrm{ppm}$ & $\Sigma Q, \mathrm{ppm}$ \\
\hline 1 & - & 350 & 0.454 & 700 & 0.321 & 0.775 \\
$1 A$ & $600^{\circ} \mathrm{C}$ & 350 & 0.042 & 700 & 0.115 & 0.157 \\
2 & - & 350 & 0.476 & 700 & 0.233 & 0.709 \\
$3 A$ & $600^{\circ} \mathrm{C}$ & 350 & 0.023 & 700 & 0.067 & 0.09 \\
$3 A$ & - & 350 & 0.03 & 700 & 0.112 & 0.142 \\
& $600^{\circ} \mathrm{C}$ & 350 & 0.043 & 700 & 0.1 & 0.143
\end{tabular}

разованию сросшейся однородной НКА-пленки уже при толщинах $\sim 100 \mathrm{~nm}$. Пленки выращивались из газовой фазы в плазме СВЧ-разряда по технологии, подробно описанной в работе [8]. В экспериментах использовались три состава газовой смеси: водород-метановая смесь при двух содержаниях метана ( $8 \%$ и $0.5 \%)$ и смесь водорода, метана и кислорода. Эти смеси позволяли получить различные пленки и оценить влияние размера кристаллитов и содержания неалмазной фазы между ними на встраиваемость водорода. Добавка кислорода в газовую смесь, согласно некоторым экспериментам [10], подавляет встраиваемость водорода в нанокристаллическую алмазную пленку. Реализованные условия и параметры режимов осаждения НКА-пленок приведены в табл. 1. При этом в каждом из режимов проводилось осаждение НКА-пленки сразу для двух образцов, один из которых в дальнейшем подвергался высокотемпературной обработке в вакууме. В табл. 1 образцы, обозначенные буквой $A$, были подвергнуты высокотемпературному отжигу в вакууме $\left(10^{-5}\right.$ Torr $)$ при температуре $600^{\circ} \mathrm{C}$ в течение часа. При этом исследования показали, что ни морфология пленок, ни их рамановские спектры не претерпевали существенных изменений. На рис. 1 приведены микрофотографии поверхности НКА-пленки, осажденной в водород-метановой смеси при $\mathrm{CH}_{4} / \mathrm{H}_{2}=8 \%$, до и после отжига в вакуумной печи.

Содержание водорода в исследуемых образцах определялось с помощью масс-спектрометрического анализатора водорода AB-1 при двух температурах экстракции $\left(T_{1}=350^{\circ} \mathrm{C}\right.$ и $\left.T_{2}=700^{\circ} \mathrm{C}\right)$ по методике, описанной в работе [11]. Было установлено, что при температуре $700^{\circ} \mathrm{C}$ из кремниевой подложки без НКА-пленки (контрольный образец) экстрагировался весь водород, а его полное содержание не превышало 0.3 ppm. В экспериментах с НКА-пленками на кремниевой подложке содержание водорода обычно заметно превышало это значение. Кроме того, можно полагать, что весь водород удаляется из кремниевых подложек в процессе осаждения алмазных пленок при температуре осаждения, превышающей $700^{\circ} \mathrm{C}$, и поэтому не вносит вклада в измерения с НКА-пленками. В качестве эталона для калибровки анализатора AB-1 использовались государственные стандартные образцы алюминиевых сплавов нового поколения [12]. Результаты измерения содержания водорода в образцах до и после их отжига приведены в табл. 2.

В табл. 2 приведены концентрации $\left(Q_{1}\right.$ и $\left.Q_{2}\right)$ водорода, выделившегося из исследуемого образца при температуре $T_{1}$ и $T_{2}$ соответственно, а также суммарное количество $(\Sigma Q) \mathrm{H}_{2}$, выделившегося при двух температурах экстракции. Из табл. 2 следует, что нагрев образцов в вакууме до температуры $600^{\circ} \mathrm{C}$ приводил к существенному снижению содержания $\mathrm{H}_{2}$ в НКА-пленках, что проявлялось в более низких значениях $Q_{1}$ для отожженных пленок (обозначенных буквой $A$ ). При этом для неотожженных образцов содержание $\mathrm{H}_{2}$ снижалось с ростом температуры $\left(Q_{1}>Q_{2}\right)$. Количество внедренного в НКА-пленку водорода зависело от концентрации метана в смеси, а также существенно падало при добавлении в смесь кислорода. Поэтому высокотемпературная 

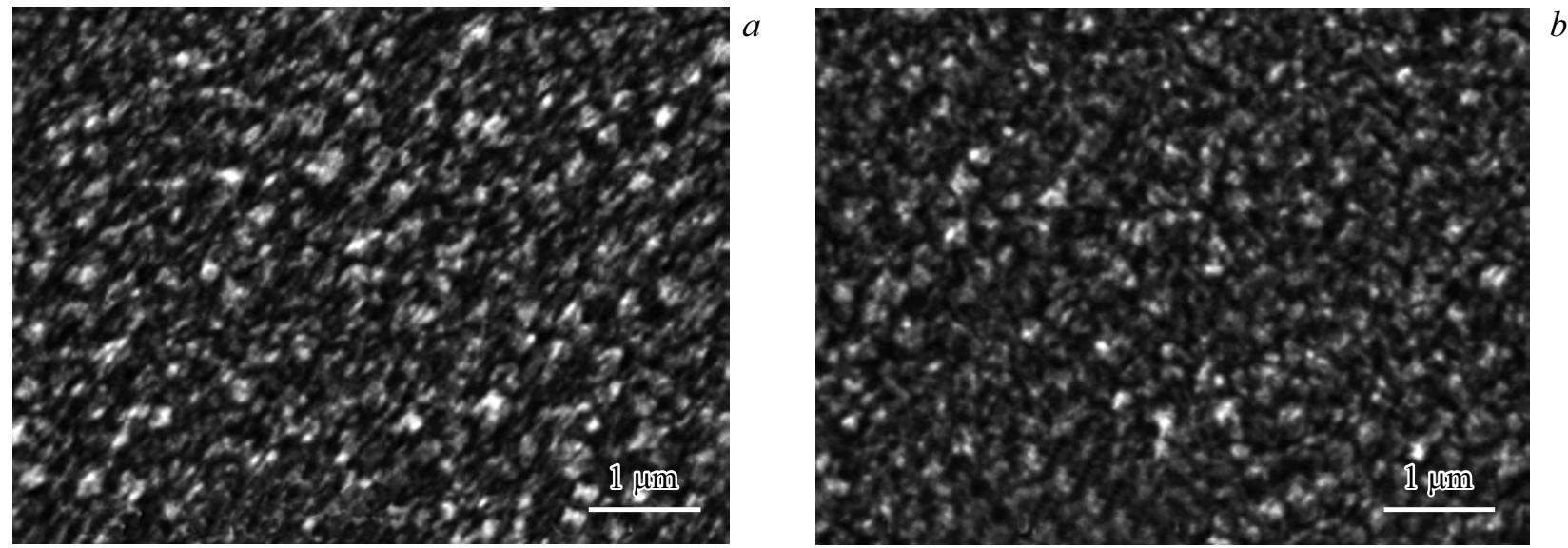

Рис. 1. Микроструктура поверхности НКА-пленки, выращенной в смеси $\mathrm{CH}_{4} / \mathrm{H}_{2}=8 \%$, до (образец 1) (a) и после (образец $\left.1 A\right)(b)$ отжига в вакуумной печи.

обработка выращенных с кислородом пленок практически не приводила к изменению его содержания в пленке. Отметим также, что, как было показано в работе [11], содержащийся в алмазных пленках водород сосредоточен в основном на границах между кристаллитами. Об этом свидетельствовало относительно низкое значение измеренной энергии связи водорода в пленке по сравнению с энергией связи $\mathrm{C}-\mathrm{H}$ или $\mathrm{C}-\mathrm{C}$ в структуре алмаза. Поэтому определенная в эксперименте концентрация $\mathrm{H}_{2}$ в пленке несколько возрастала для образцов с большим содержанием $s p^{2}$-фазы (значения $\Sigma Q$ для образцов 1 и 2).

На следующем этапе было проведено измерение сопротивления выращенных НКА-пленок до и после их термической обработки. Сопротивление пленок определялось двухзондовым методом на основе анализа вольтамперных характеристик (BAX), получаемых с помощью измерителя BAX (KEYSIGT B2901A) в диапазоне \pm 20 V. Измерения проводились по схеме контакт на поверхности пленки-НКА-пленка-проводящая подложка $\mathrm{Si}$ (n-тип) с индиевым контактом и подробно описаны в работе [8]. ВАХ всех исследованных образцов, как правило, имели квазисимметричную форму с линейной (омической) частью в указанном диапазоне напряжений. Отметим, что симметричный вид характеристик и их линейность в довольно широкой области напряжений свидетельствуют об омическом характере контактов. Вид ВАХ исследуемых образцов до и после их высокотемпературной обработки в вакууме при температуре $600^{\circ} \mathrm{C}$ представлен на рис. 2.

Из приведенных рисунков следует, что высокотемпературная обработка приводит к существенному возрастанию сопротивления НКА-пленок. Так, сопротивление пленки, определенное по наклону ВАХ (рис. 2), при переходе от образца 1 к образцу $1 A$ возрастало от значения $R_{1}=(2-3) \cdot 10^{8} \Omega$ до $R_{1 A}=(4-5) \cdot 10^{9} \Omega$, для образца 2 - от $R_{2}=6 \cdot 10^{6} \Omega$ до $R_{2 A}=2.3 \cdot 10^{7} \Omega$, а для образца 3 - от $R_{3}=3.8 \cdot 10^{7} \Omega$ до $R_{3 A}=6.5 \cdot 10^{7} \Omega$. Эти данные хорошо коррелируют с измерениями содержания водорода в пленках (табл. 2), т.е. уменьшение содержания водорода в пленке при высокотемпературном отжиге сопровождается уменьшением ее проводимости. Отметим также, что добавка кислорода в водород-метановую смесь приводила к более низкому содержанию $\mathrm{H}_{2}$ в НКА-пленке и, как следствие, возрастанию ее сопротивления. При этом из-за более низкого содержания $\mathrm{H}_{2}$ в такой пленке изменение ее сопротивления при отжиге не столь существенно (рис. 2,c). Такое влияние кислорода качественно можно объяснить изменением плазмохимических процессов в плазме, появлением радикалов О и ОН, которые участвуют в травлении графита (наряду с атомами водорода), а также вступают в реакции с радикалами углеводорода $\mathrm{CH}$ и $\mathrm{CH}_{2}$, уменьшая концентрацию радикалов, ответственных за включение водорода в пленку [13].

Таким образом, в работе продемонстрировано прямое определение концентрации водорода в НКА-пленках с помощью стандартного промышленного оборудования. Показано, что водород, внедренный в НКА-пленку в процессе ее роста, оказывает существенное влияние на ее электрические характеристики, увеличивая электропроводность пленки. Концентрация водорода в пленках, выращенных в водород-метановой смеси, растет с увеличением содержания метана и соответственно доли неалмазной фазы в пленках. При этом высокотемпературная обработка в вакууме позволяет удалить водород из пленок и, следовательно, увеличить их сопротивление. Малая добавка кислорода в газовую смесь приводит к подавлению процесса встраивания водорода в пленку и позволяет получить высокие сопротивления, не подвергая пленки высокотемпературной обработке. Эксперименты показали, что с помощью выбора режима роста пленок и их послеростовой обработки возможно получение нелегированных НКА-пленок с различными изоляционными характеристиками. 

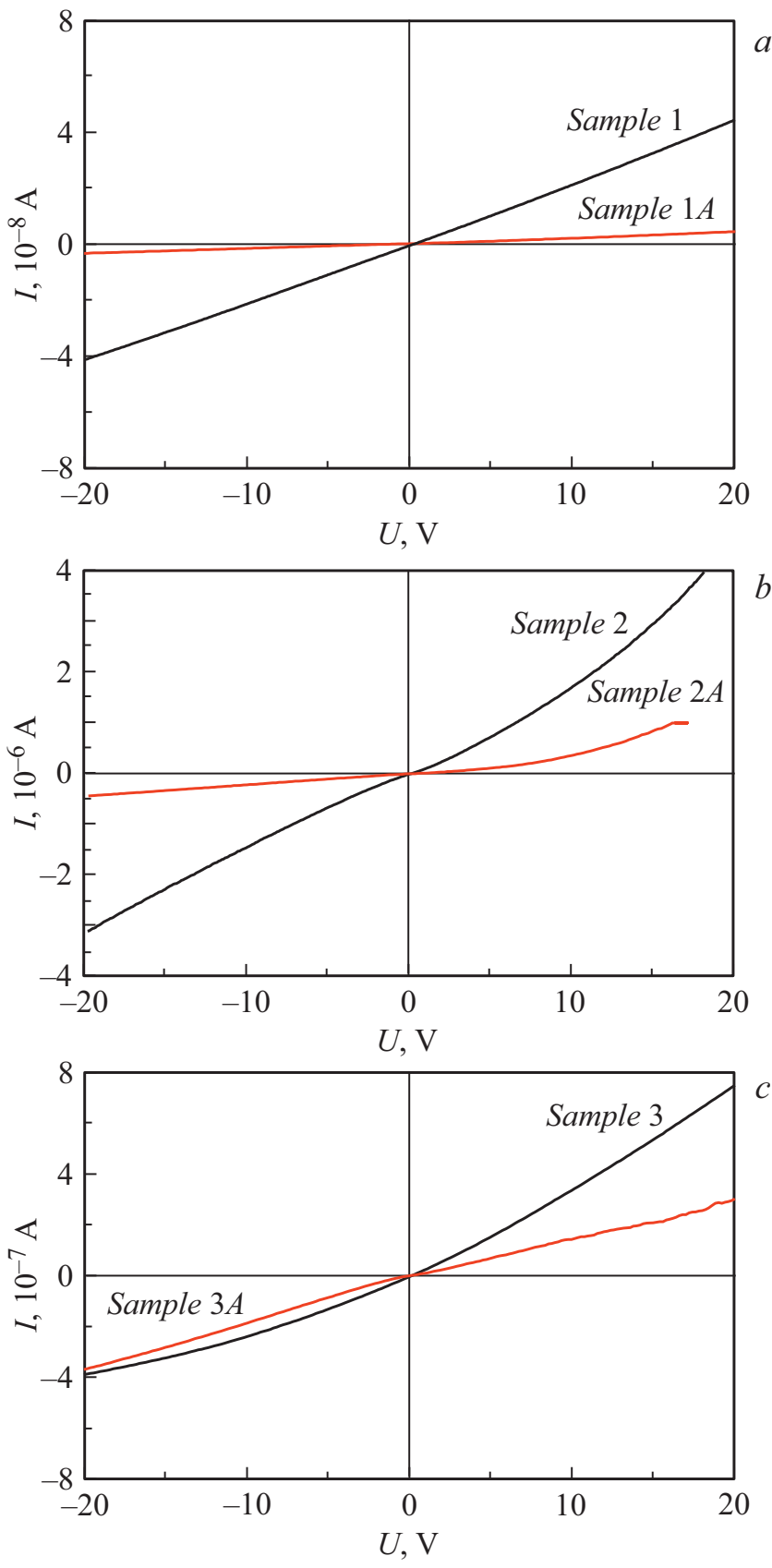

Рис. 2. Вольт-амперные характеристики НКА-пленок до (образцы $1-3$ ) и после (образцы $1 A-3 A$ ) отжига в вакууме при $600^{\circ} \mathrm{C} . a-$ образцы 1 и $1 A\left(\mathrm{CH}_{4} / \mathrm{H}_{2}=8 \%\right) ; b-$ образцы 2 и $2 \mathrm{~A}\left(\mathrm{CH}_{4} / \mathrm{H}_{2}=0.5 \%\right) ; c-$ образцы 3 и $3 \mathrm{~A}\left(\mathrm{CH}_{4} / \mathrm{H}_{2}=0.5 \%\right.$, $\left.\mathrm{O}_{2} / \mathrm{H}_{2}=0.1 \%\right)$.

\section{Финансирование работы}

Работа выполнена в рамках государственного задания Федерального исследовательского центра Институт прикладной физики РАН (проект № 0030-2021-0003).

\section{Конфликт интересов}

Авторы заявляют, что у них нет конфликта интересов.

\section{Список литературы}

[1] O.A. Williams, M. Nesládek, J.J. Mareš, P. Hubík, in Physics and applications of CVD diamond, ed. by S. Koizumi, C. Nebel, M. Nesladek (Wiley-VCH, 2008), p. 13.

[2] J. Kusterer, E Kohn, in CVD diamond for electronic devices and sensors, ed. by R.S. Sussmann (Wiley, 2009), p. 469.

[3] A.V. Sumant, O. Auciello, R.W. Carpick, S. Srinivasan, J.E. Butler, MRS Bull., 35, 281 (2010). DOI: $10.1557 / \mathrm{mrs} 2010.550$

[4] I.-N. Lin, S. Koizumi, J. Yater, F. Koeck, MRS Bull., 39, 533 (2014). DOI: $10.1557 / \mathrm{mrs} .2014 .101$

[5] K.J. Sankaran, K. Haenen, in: Novel aspects of diamond, ed. by N. Yang (Springer, 2019), p. 123.

[6] O. Auciello, J. Birrell, J. Carlisle, J. Gerbi, X. Xiao, B. Peng, H. Espinosa, J. Phys.: Condens. Matter, 16, 539 (2004). DOI: $10.1088 / 0953-8984 / 16 / 16 /$ R02

[7] M. Lions, S. Saada, M.A. Pinault, F. Andrieu, O. Faynot, P. Bergonzo, AIP Conf. Proc., 1292, 129 (2010). DOI: $10.1063 / 1.3518278$

[8] А.Л. Вихарев, С.А. Богданов, Н.М. Овечкин, О.А. Иванов, Д.Б. Радищев, А.М. Горбачев, М.А. Лобаев, А.Я. Вуль, А.Т. Дидейкин, С.А. Краев, С.А. Королев, ФТП, 55 (1), 49 (2021). DOI: 10.21883/FTP.2021.01.50387.9520

[9] C.A. Zorman, G.T. Mearini, R.W. Hoffman, Diamond Relat. Mater., 9, 1518 (2000). DOI: $10.1016 / \mathrm{S} 0925-9635(00) 00278-8$

[10] C.J. Tang, L.P. Gu, J. Gracio, J.L. Ribeiro, Phys. Status Solidi A, 206, 2816 (2009). DOI: 10.1002/pssa.200925147

[11] А.М. Полянский, В.А. Полянский, Ю.А. Яковлев, Н.А. Феоктистов, В.Г. Голубев, А.Я. Вуль, Письма в ЖТФ, 41 (11), 56 (2015).

[12] А.М. Полянский, Л.А. Конопелько, В.А. Полянский, Ю.А. Яковлев, Измерительная техника, № 9, 65 (2019). DOI: 10.32446/0368-1025it.2019-9-65-71

[13] S.J. Harris, A.M. Weiner, Appl. Phys. Lett., 55, 2179 (1989). DOI: $10.1063 / 1.102350$ 